Article

\title{
Designing Rainwater Harvesting Systems Cost-Effectively in a Urban Water-Energy Saving Scheme by Using a GIS-Simulation Based Design System
}

\section{Yie-Ru Chiu ${ }^{1}$, Yao-LungTsai ${ }^{2, *}$ and Yun-Chih Chiang ${ }^{3}$}

1 Center for General Education, Tzu-Chi University, No.701, Zhongyang Rd., Sec.3, Hualien 97004, Taiwan; E-Mail: chiuyr@gmial.com

2 Department of Leisure and Recreation Studies, Aletheia University, No.70-11 Pei-Shi Liao, Matou, Tainan 72147, Taiwan

3 Center for General Education, Tzu-Chi University, No.701, Zhongyang Rd., Sec.3, Hualien 97004, Taiwan; E-Mail: ycchiang@mail.tcu.edu.tw

* Author to whom correspondence should be addressed; E-Mail: yltsai2011@gmail.com; Tel.: +886-6-570-3100 (ext. 7419); Fax: +886-6-570-3834.

Academic Editor: Ataur Rahman

Received: 20 September 2015 / Accepted: 3 November 2015 / Published: 10 November 2015

\begin{abstract}
Current centralized urban water supply depends largely on energy consumption, creating critical water-energy challenge especially for many rapid growing Asian cities. In this context, harvesting rooftop rainwater for non-potable use has enormous potential to ease the worsening water-energy issue. For this, we propose a geographic information system (GIS)-simulation-based design system (GSBDS) to explore how rainwater harvesting systems (RWHSs) can be systematically and cost-effectively designed as an innovative water-energy conservation scheme on a city scale. This GSBDS integrated a rainfall data base, water balance model, spatial technologies, energy-saving investigation, and economic feasibility analysis based on a case study of eight communities in the Taipei metropolitan area, Taiwan. Addressing both the temporal and spatial variations in rainfall, the GSBDS enhanced the broad application of RWHS evaluations. The results indicate that the scheme is feasible based on the optimal design when both water and energy-savings are evaluated. RWHSs were observed to be cost-effective and facilitated $21.6 \%$ domestic water-use savings, and 138.6 (kWh/year-family) energy-savings. Furthermore, the cost of per unit-energy-saving is lower than that from solar PV systems in $85 \%$ of the RWHS settings. Hence, RWHSs not only enable water-savings, but are also an alternative
\end{abstract}


renewable energy-saving approach that can address the water-energy dilemma caused by rapid urbanization.

Keywords: economic feasibility; energy saving; geographic information system GIS; rainwater harvesting; water resources conservation

\section{Introduction}

Current centralized urban water supply systems depend largely on energy consumption in all processing phases, including purification, distribution, and sewage treatment [1,2]. However, only recently has attention been focused on exploring the connection between urban water supply and the associated energy consumption, known as the water-energy nexus [3-5]. In this context, the water-energy challenge is increasingly critical because of rapid urbanization [6-8]. Certain studies have also suggested that the synergistic impact of energy and water consumption portends more serious consequences if not addressed appropriately. In addition, future research should address challenges such as the environmental impact of urban water supply and energy production, and should develop models that jointly address energy and water conservation for the development of water and energy resilient cities [9-12]. Because rainwater is the most fundamental renewable resource, it can be harvested on-site and used for non-potable purposes (e.g., flushing toilets and gardening), without requiring complicated treatment and long-distance transportation. Therefore, the innovative conservation ability of rainwater harvesting systems (RWHSs) has the potential to ease the water-energy dilemma caused by rapid urbanization.

For many fast growing Asian cities with limited flat areas, such as Tokyo, Taipei, Seoul, and, Chongqing, water-energy concerns are further exacerbated, because the hilly areas surrounding the cities have often been developed into suburbs to accommodate fast growing urban populations $[7,8,13]$. Additional energy is required to pump water to these communities, which enlarges the ecological footprint $[14,15]$. To improve the water-energy efficiency of communities that live in hilly areas around large cities, attention should be focused on how to systematically and cost-effectively design RWHSs in a city scale. An integrated approach should be followed to shift focus from individual RWHSs to overall system performance. Research in this domain often uses historical rainfall data to simulate the hydraulic performance of individual RWHSs, predict economic feasibility, and seek optimal design [15-20]. The best known storage sizing for RWHSs is the water balance model. A review of the literature revealed that the water balance equation has been accepted and adopted by researchers to simulate the behavior of RWHSs, and to predict their performance [16,18,20-27]. RWHSs in dense urban areas appear to be economically advantageous [28-30]. To understand the energy-saving capacity of RWHSs, Retamal et al. [31]; Proença et al. [3]; Siddiqi and Anadon [32]; Abdallah and Rosenberg [33] have explored the energy saved due to RWHS system implementation, however, only single RWH sets are discussed. Because the frequency and amount of rainfall may also vary spatially, the primary disadvantage of a single-site approach lies in its improper treatment of the spatial aspect when large scale assessment is required [34]. To address the constraint attributed to both spatial and temporal variation of rainfall, some researchers used classified regions to present the spatial 
effect in the RWHS design [21,24,27]. To be more precise in the spatial analysis, Chiu and Liaw [34] incorporated water balance model into their geographic information system (GIS) and visualized the results, which resulted in a more comprehensive understanding of RWHSs. However, only the water-saving impact was considered and the water-energy nexus was not included in their analyses; consequently, the energy-saving effect and associated economic feasibility of RWHSs to enhance urban water-energy conservation remains unknown to the general public. Therefore, energy savings, spatial-based water balance model, and economic feasibility analysis should be carefully integrated. Only when communities and urban planners have received comprehensive and integrated information to improve their understating of RWHSs will they be able to make sound decisions when planning the water-energy conservation schemes of large cities.

This study established a GIS-simulation-based design system (GSBDS) that incorporated a historical rainfall data base, water balance model, spatial-based technologies, energy saving analysis, and economic feasibility analysis. This GSBDS case study was based on eight communities located in the hills around the Taipei metropolitan area in Northern Taiwan. The study's purpose was threefold: first, to perform a spatially-based simulation that addressed the temporal and spatial variation of rainfall together to enhance and visualize the performance of RWHSs; second, to obtain the optimal tank volumes of RWHSs and the associated total water and energy savings; and finally, to identify RWHS as an energy-saving approach for communities based in hilly areas by comparing them with another popular energy-saving approach, namely, solar photovoltaic (solar PV) system.

\section{GSBDS Approach}

\subsection{System Description}

The GSBDS consists of three parts, namely a data base, data processing, and data input and output, as illustrated in Figure 1. The data base included rainfall data, community data, and economic data, and data processing included water balance model, spatial interpolation, and economic feasibility analysis. The GSBDS application can be described as follows:

(1) The historical rainfall data of each rainfall station is first used for simulation based on water balance model to derive the water saving performance of RWHS in these stations. The results were then spatially interpolated to quantify and visualize the spatial distribution, and to predict annual water savings of the assigned RWHSs for communities based in hilly areas.

(2) Based on the water-energy coefficient derived from the community data and cost analysis of RWHSs, an economic feasibility analysis could be conducted to determine the cost-effectiveness of all RWHSs and thus identified optimal volumes of tanks.

(3) Using the optimized design of RWHSs, the total water-energy savings in the study area could be calculated, and the unit energy saving cost obtained to compare it with other energy saving approaches.

Water balance model and economic analysis were performed using VBA in SuperGIS 2.1 and SQL to access the data base [34]. The details of the water balance model, spatial interpolation, water-energy relation, and economic feasibility analysis are described below. 


\subsection{Spatial Interpolation}

Various methods for spatial interpolation, including Kriging, Tend, Spline, Thissen Polygon, Multivariate Regression, and Inverse Distance Weighted (IDW) have been developed to estimate the value of properties at sites without observational data [35]. However, none of these has been accepted as the standard method. In Taiwan, the IDW $(p=2)$ method was reported effective to interpolate rainfall data in Northern Taiwan, and was therefore adopted for this study [36]. The IDW was calculated using the GIS software, SuperGIS 2.1 [37].

\subsection{Water Balance Model}

For most RWHSs, the efficiency of rainwater supply depends on four major parameters, namely, rainfall depth, rooftop area, tank volume, and water demand. Our GSBDS incorporated the Yield-Before-Spillage (YBS) release rule with time step of daily [38], which determines the demand withdrawn before spillage.

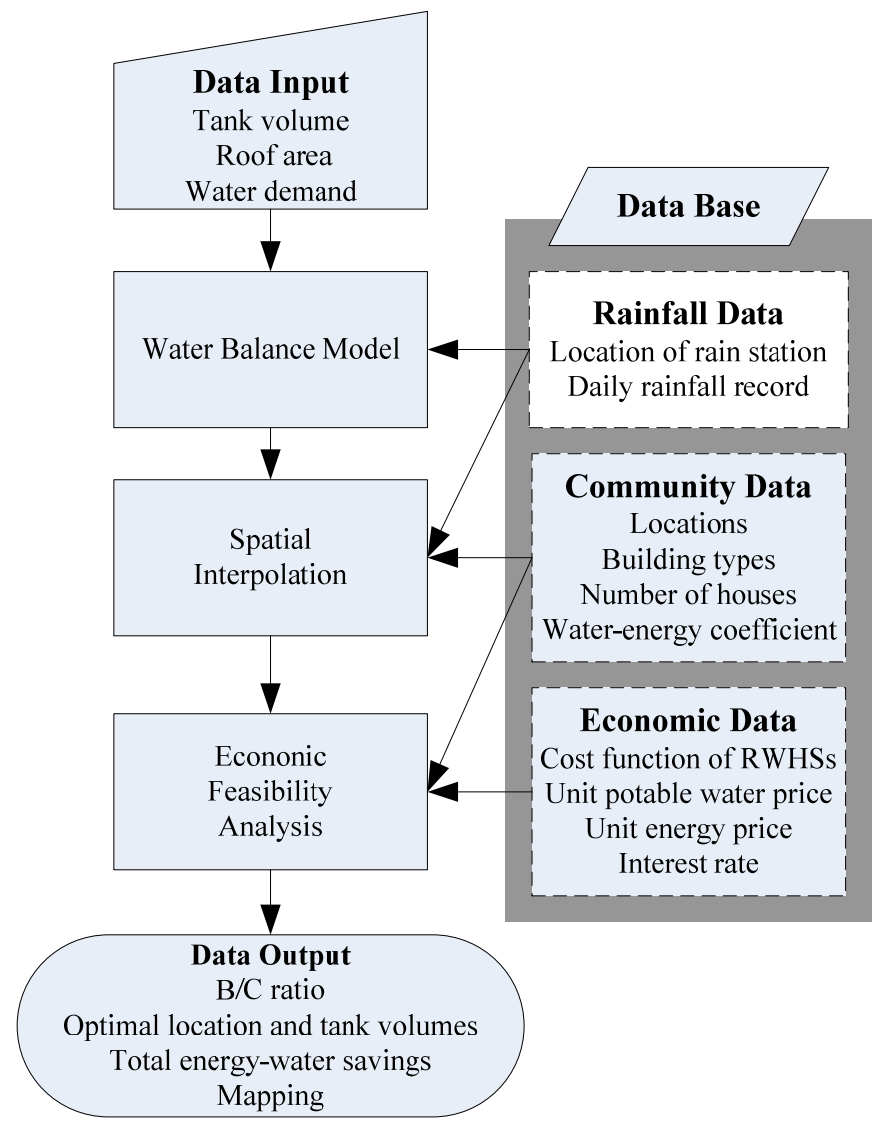

Figure 1. Conceptual framework of GSBDS.

The operational algorithm of YBS can be mathematically described as follows:

$$
\begin{gathered}
Y_{t}=\operatorname{Min}\left(D_{t}, S_{t-1}\right) \\
S_{t}=\operatorname{Min}\left(S_{t-1}+Q_{t}-Y_{t}, V\right) \\
Q_{t}=C \cdot I_{t} \cdot A
\end{gathered}
$$


where $Y_{t}$ is the rainwater yield $\left(\mathrm{m}^{3}\right)$ during the $t^{\text {th }}$ period; $D_{t}$ is water demand $\left(\mathrm{m}^{3}\right)$ at time $t ; S_{t-1}$ is storage volume $\left(\mathrm{m}^{3}\right)$ of rainwater in the tank at the $t-1^{\text {th }}$ period; $V$ denotes tank volume $\left(\mathrm{m}^{3}\right) ; Q_{t}$ denotes the rooftop rainwater runoff $\left(\mathrm{m}^{3}\right) ; I_{t}$ is rainfall depth (m) at time $t ; A$ is catchment area $\left(\mathrm{m}^{2}\right)$; and $C$ is the runoff coefficient (runoff/rainfall volume). (setting 0.82 as recommended by Liaw and Tsai [17]).

Based on the design factors (i.e., $A, D_{t}, V$ ) and the rainfall data of a rainfall station, the hydraulic performance (annual potable water savings $W S\left(\mathrm{~m}^{3} /\right.$ year) of the RWHS of a rainfall station could be achieved and can be expressed as follows:

$$
W S=\frac{\sum_{t=1}^{n} Y_{t}}{n} 365
$$

where $n$ denotes the total number of daily rainfall data. To estimate the $W S$ of various communities (WSi of $i^{\text {th }}$ community), a spatial interpolation method based on the WS of each rainfall station was subsequently adopted.

\subsection{Water-Energy Nexus}

Before exploring the economic feasibility of RWHSs for water-energy savings, the relationship between potable water consumption and energy consumption, namely water-energy coefficient $\beta\left(\mathrm{kWh} / \mathrm{m}^{3}\right)$, had to be assessed. Typically, potable water from purifying plants is first pumped by urban pump stations supplying water to both flat and hilly areas, and then pumped by a series of hilly area pump stations to communities based in the area. Cheng [1] investigated the water-energy coefficients in downtown areas of Taipei City, and reported an average of $0.22 \mathrm{kWh} / \mathrm{m}^{3}$ for water purifying, $0.17 \mathrm{kWh} / \mathrm{m}^{3}$ for urban pumping, and $0.41 \mathrm{kWh} / \mathrm{m}^{3}$ for sewage treatment. However, because of the difficulties involved in collecting data, water-energy coefficients for pumping in hilly areas were unknown and required further investigation.

The amount of energy required to pump water depends on a number of factors, including lift, water flow, pump efficiency, transmission efficiency, and friction-loss of pipes, and can be simplified by measuring the power of pumps and the water flow [39]. Each participating community's water-energy coefficient for pumping in hilly areas can be mathematically defined as follows:

$$
\beta_{H i l l y, i}=\sum_{j} \beta_{H i l l y, i, j}=\sum_{j} \frac{R_{p, i, j} \cdot 0.746 \cdot(1 / \eta)}{Q_{p, i, j} \cdot(1 / 24)}
$$

where $\beta_{H i l l y, i}$ is the water-energy coefficient of $i^{\text {th }}$ hilly community; $\beta_{H i l l y, i, j}$ denotes the water-energy coefficient for the $j^{\text {th }}$ hilly pump station in $i^{\text {th }}$ community; $R_{p, i, j}$ is pump power (hp) in $j^{\text {th }}$ hilly pump stations in $i^{\text {th }}$ hilly community; $\eta$ is mechanical efficiency (\%), and $Q_{p, i, j}$ is the water flow $\left(\mathrm{m}^{3} / \mathrm{d}\right)$.

The cost of purifying water and urban pumping are typically included in water fees, and are therefore regarded as external effects in the economic analysis. In addition, applying RWHSs to flushing toilets and gardening cannot reduce the amount of water used for sewage treatment. Therefore, the energy cost for sewage treatment was also excluded from the economic analysis presented in the next section. However, when the total energy savings and the associated $\mathrm{CO}_{2}$ emissions are required to be considered, the water-energy coefficient for water purifying ( $\beta_{\text {Purifing }}$ ) and 
urban pumping of associated $i^{\text {th }}$ community $\left(\beta_{\text {Urban, }, i}\right)$ have to be included. In this case, the total water-energy coefficient of $i^{\text {th }}$ community $\left(\beta_{\text {Total, } i}\right)$ can be expressed as follows:

$$
\beta_{\text {Total }, i}=\beta_{\text {Purifing }}+\beta_{\text {Urban }, i}+\beta_{\text {Hilly }, i}
$$

The operational energy used in RWHSs may vary according to the types of RWHS design. Vieira et al. (2014) [40] reviewed literatures and reported that the energy consumption per unit rainwater supply may be far higher than that in centralized urban water systems when direct pumps are adopted to supply stored rainwater to end users. This is because the energy used for pump start-ups and standby mode is often underestimated. However, the energy efficiency of pumps can be enhanced when RWHSs are based on gravity rainwater supply by using rainwater header tanks [40]. Rainwater from roofs is first collected in the storage tanks on the ground, and then pumped to the header tanks that usually are placed on the roofs or on the higher position in the buildings. The header tanks supply water via gravity and are commonly installed with dual-inlet float valves that supply potable water when rainwater storage tanks are empty. In Taiwan, the header tank's design is common and widely adopted to store potable water. This study also adopted RWHSs designed with rainwater header tanks, and thereby assumed the operational energy consumption of RWHSs to be negligible in the case study, because the energy used for pumping stored rainwater to header rainwater tanks can be compensated by reducing pumping water to the potable header tanks.

\subsection{Economic Feasibility Analysis and the Optimal Design}

The economic feasibility of this RWHS was determined by its benefit-cost $(\mathrm{B} / \mathrm{C})$ ratio, where a B/C ratio greater than 1 was considered cost-effective. To simplify the calculation, the cost and benefit of RWHS were both expressed in unit form, as well as in New Taiwan Dollars (US\$1 = NT\$32.5). The cost of unit water savings ( $U W S C_{i, v}, \mathrm{NT} \$ / \mathrm{m}^{3}$, for $i^{\text {th }}$ community using $V$ tank) and the cost of unit energy saving (UESC $i, v, \mathrm{NT} \$ \mathrm{kWh}$, for $i^{\text {th }}$ community using $V$ tank volume) could be derived from the results of GSBDS data processing (Figure 1), using water balance model, spatial interpolation, and Equation (5). The $U W S C_{i, v}$ and $U E S C_{i, v}$ can be written as follows:

$$
\begin{gathered}
U W S C_{i, v}=\frac{C_{v}}{W S_{i, v}} \\
U E S C_{i, v}=\frac{C_{v}}{\beta_{H i l l y, i} \cdot W S_{i, v}}
\end{gathered}
$$

where $C_{v}$ is the annualized cost of RWHS, using $V$ tank volume; and $W S_{i, v}$ denotes annual potable water saved in $i^{\text {th }}$ community, using $V$ tank volume.

A larger tank volume implies more water saved and a greater contribution to energy savings, but is less cost-effective. Therefore, we assumed that the largest tank volume that remained cost-effective to be the optimal design for the GSBDS.

Customarily, water conservation and energy conservation are rarely planned together. For this reason, the $B / C$ ratios of $i^{\text {th }}$ community with $V$ tank volume were examined in terms of three scenarios: Scenario 1

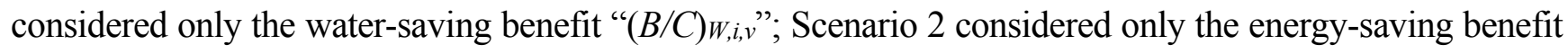
" $(B / C)_{E, i, v " ;}$; and Scenario 3 considered both water and energy savings " $(B / C) W+E, i, v "$ : 
Scenario 1:

$$
(B / C)_{W, i, v}=\frac{U W F}{U W S C_{i, v}}
$$

Scenario 2:

$$
(B / C)_{E, i, v}=\frac{U E F}{U E S C_{i, v}}
$$

Scenario 3:

$$
(B / C)_{W+E, i, v}=\frac{U W F+\beta_{H i l y, i} \cdot U E F}{U W S C_{i, v}}
$$

where $U W F$ denotes the unit potable water fee $\left(\$ / \mathrm{m}^{3}\right)$, and $U E F$ is the unit electricity fee $(\$ / \mathrm{kWh})$. The $U W F$ and $U E F$ were considered as benefits of unit savings in this analysis.

Based on this optimal design, the contribution of applying RWHS to a water-energy conservation scheme could be described using the total potable water savings per year $T W S\left(\mathrm{~m}^{3} /\right.$ year), and the total energy savings per year TES (kWh/year):

$$
\begin{gathered}
T W S=\sum W S_{i} \cdot N_{i} \\
T E S=\sum W S_{i} \cdot \beta_{\text {Total }, i} \cdot N_{i}
\end{gathered}
$$

where $N_{i}$ is the number of buildings of selected building type in $i$ th community.

\section{Background and Data Sources}

Taipei is the largest metropolitan area in Taiwan and includes both Taipei City and New Taipei City which is located in the Taipei Basin, and is well-known for its large population of 6.36 million (in year 2014). Because Taipei's development is constrained by a limited plain area, government and private enterprises have launched several large community projects in the surrounding hills since the early 1980s. As a case study, rooftop RWHSs were assumed in these communities and applied in the GSBDS. The rainfall data, RWHSs cost, and community data can be described as follows.

\subsection{Rainfall Data}

The rainfall data base included the daily rainfall data from 31 automatic rain data collection stations (15 inside and 16 around Taipei City, collected from 1994 to 2013). Mitchell et al. [41] and Campisano et al. [42] have suggested that the favorable rainfall data set consistency is at minimum 25 years for making a reliable simulation. However, in this case study, out of 31 rainfall stations, some of them do not provide complete and reliable rainfall data before 1994. Based on the suggestion from previous study and the reality of available data set, this study adopt 20 years of rainfall data for simulation in a large scale. Among them, the average annual rainfall was $3127 \mathrm{~mm} /$ year, the lowest was $1321 \mathrm{~mm} /$ year, and the highest was $6124 \mathrm{~mm} /$ year. Despite an annual rainfall difference of nearly 4.6 times, the distance between these two stations is only $17.2 \mathrm{~km}$, revealing how substantially the spatial factor affects the performance of RWHSs, and highlights the importance of adopting a spatial 
approach. Figure 2 indicates the locations of the rainfall stations and the spatial variances of average annual rainfall where the northeastern area is higher and northwestern area is lower.
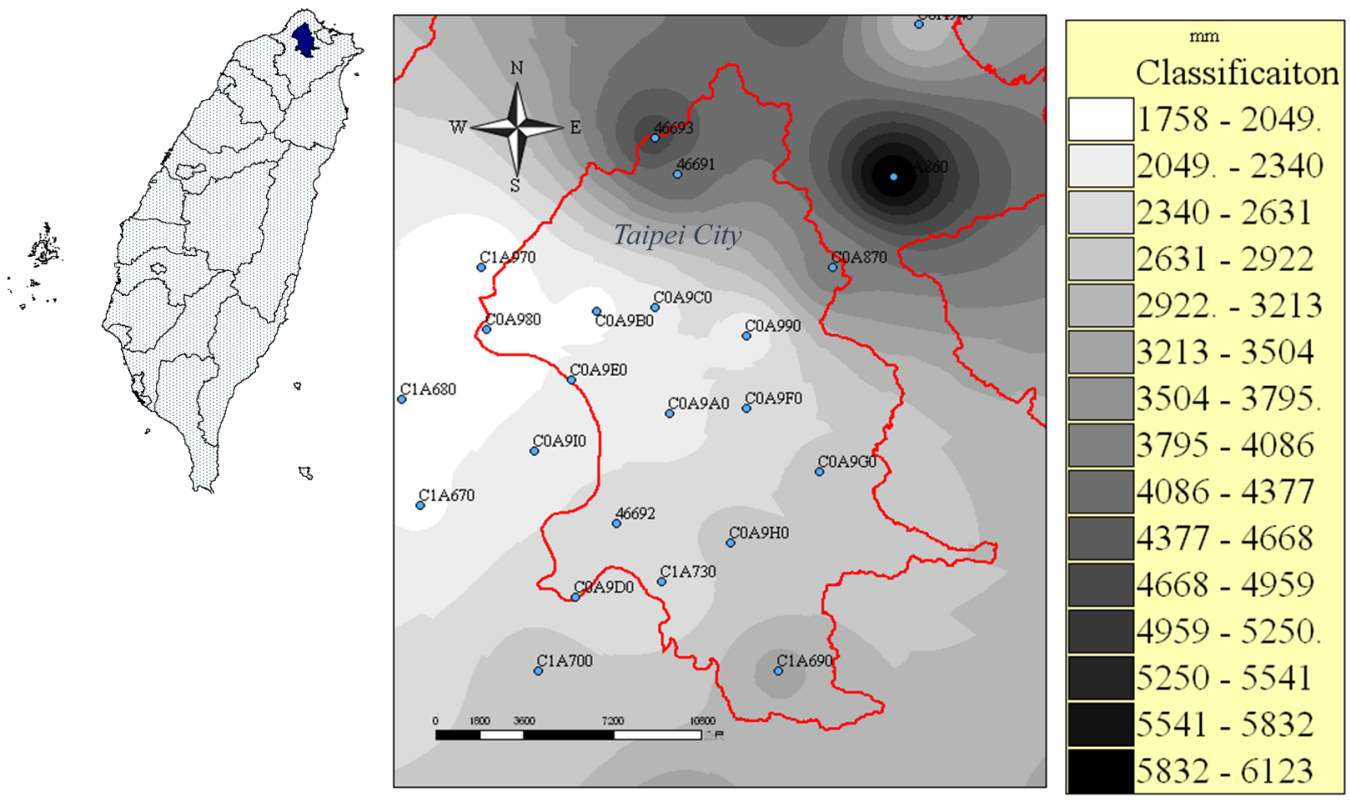

Figure 2. Average annual rainfall and the locations of rainfall stations.

\subsection{Water Quality Issue and the Cost of RWHSs}

The typical rooftop RWHSs consists of four basic sub-systems, namely a catchment system, pipeline system, treatment system, and tank system. The level of treatment to achieve acceptable water quality might substantially influence the cost of RWHSs. In Taiwan, the Water Resources Agency (WRA) established a recommended contaminant level for rainwater harvested from rooftops to flush toilets [43]. Because biological oxygen demand (BOD) and free chloride surplus are not regulated, appropriately installed RWHSs with simple filters typically meet the rainwater reuse standard.

Chiu et al. $[38,44]$ surveyed market prices to develop a cost function for RWHSs in Northern Taiwan using the judgment sampling technique. We adopted the most commonly used cylindrical stainless steel tank, with a 25 -year lifespan; $5 \%$ of the total cost for maintenance; and 3\% discount rate which is recommended by the Taiwanese government for evaluating public projects. The annualized cost function $C(V)$ of RWHSs of this type of tank can be expressed as follows:

$$
C(V)=944.65+34.10 \cdot V^{2}, V \geq 1, R^{2}=0.997
$$

where $V\left(\mathrm{~m}^{3}\right)$ is tank volume.

\subsection{Community Data}

Among all the communities based in the hilly areas of the Taipei metropolitan area, hilly area pump stations in eight communities are maintained by the main public utility operator, the Taipei Water Department (TWD). The other pump stations are maintained by private construction companies or associated community committees. In this case study, pump station data from the eight hill communities maintained by the main public utility were analyzed and adapted to the GSBDS. 
Table 1 lists details of the eight communities that formed part of this study. A sequence number was assigned according to the respective average annual rainfall obtained by interpolating the data from rainfall stations.

Table 1. Details of hilly communities with pumping stations managed by TWD.

\begin{tabular}{|c|c|c|c|c|c|c|c|c|c|c|}
\hline \multirow{2}{*}{$i$} & \multirow{2}{*}{ Community } & \multirow{2}{*}{$N_{\mathrm{i}}$} & \multirow{2}{*}{$\begin{array}{c}\text { Rainfall } \\
(\mathbf{m m})\end{array}$} & \multirow{2}{*}{ Longitude } & \multirow{2}{*}{ Latitude } & \multirow{2}{*}{$\boldsymbol{\beta}_{\text {Urban, } i}$} & \multicolumn{4}{|c|}{$\beta_{H i l l y, I, j}$} \\
\hline & & & & & & & $j=1$ & $j=2$ & $j=\mathbf{3}$ & $j=4$ \\
\hline 1 & Yie She & 597 & 2744 & $25^{\circ} 00^{\prime} 27.21^{\prime \prime}$ & $121^{\circ} 34^{\prime} 01.31^{\prime \prime}$ & 0.22 & 0.338 & 0.573 & - & - \\
\hline 2 & Rose China & 720 & 2867 & $24^{\circ} 56^{\prime} 46.06^{\prime \prime}$ & $121^{\circ} 34^{\prime} 43.12^{\prime \prime}$ & 0.17 & 0.331 & 0.166 & 0.197 & - \\
\hline 3 & Taipei small town & 1418 & 2911 & $24^{\circ} 56^{\prime} 44.40^{\prime \prime}$ & $121^{\circ} 29^{\prime} 59.90^{\prime \prime}$ & 0.17 & 0.191 & 0.406 & 1.043 & 0.796 \\
\hline 4 & Wan Fan & 225 & 2941 & $25^{\circ} 00^{\prime} 04.85^{\prime \prime}$ & $121^{\circ} 34^{\prime} 08.45^{\prime \prime}$ & 0.17 & 0.358 & 0.177 & - & - \\
\hline 5 & Ju Chun Li & 239 & 3031 & $25^{\circ} 01^{\prime} 50.21^{\prime \prime}$ & $121^{\circ} 39^{\prime} 57.94^{\prime \prime}$ & 0.22 & 0.249 & 0.904 & 0.266 & \\
\hline 6 & Chi Nan & 152 & 3059 & $24^{\circ} 59^{\prime} 20.88^{\prime \prime}$ & $121^{\circ} 35^{\prime} 07.47^{\prime \prime}$ & 0.22 & 0.628 & 0.628 & 0.419 & 0.266 \\
\hline 7 & Tan shi Shan & 116 & 3108 & $24^{\circ} 56^{\prime} 53.79^{\prime \prime}$ & $121^{\circ} 31^{\prime} 59.90^{\prime \prime}$ & 0.22 & 0.744 & - & - & - \\
\hline 8 & Mu Ja 2 phase & 585 & 3255 & $24^{\circ} 56^{\prime} 20.88^{\prime \prime}$ & $121^{\circ} 35^{\prime} 07.47^{\prime \prime}$ & 0.22 & 0.331 & 0.124 & - & - \\
\hline
\end{tabular}

$N_{i}$ is the number of buildings of selected building type in $i^{\text {th }}$ community, which also refers to the total number of RWH systems. Because various types of buildings exist in these communities, the most common types of building, a building with a $100-\mathrm{m}^{2}$ rooftop area supplying water for a family's toilet flushing, and a $20-\mathrm{m}^{2}$ garden area, were selected for this study to further simplify the calculations.

Another critical design consideration was water demand. Based on the government's $250 \mathrm{~L}$ per capita per day suggestion (Lpcd) for indoor water consumption, of which $24 \%$ is used for toilet flushing in a typical four-member household [45]. The gardening water demand was set to $3.0 \mathrm{~mm} / \mathrm{d}$ based on the recommendation of the Technical Guideline for Soil and Water Conservation [46].

\section{Results and Discussion}

\subsection{Results of Simulation}

The results of the spatially interpolated WS and the locations of the hill communities are presented in Figure 3. The spatial variation of WS agreed with the spatial distribution of average annual rainfall as demonstrated in Figure 2; however, further analysis is required to understand the performance of RWHSs on a large scale. Several previous studies used the generalized method that simply applies a constant usage rate to the average annual or monthly rainfall data without addressing the temporal variation of rainfall $[47,48]$. Figure 4 clearly shows the inconsistent of average annual rainfall and $W S_{i}$ of each community using most commercially available tank volumes, i.e., 1,3 and $5 \mathrm{~m}^{3}$. This discrepancy occurred because of the difference in rainfall patterns. For example, despite similar average annual rainfall, RWHSs in areas with an uneven temporal distribution of rainfall tended to be less efficient than those with even distribution, because excess rainwater in a single rainfall event eventually overflows without being used. Therefore, the GSBDS used both water balance model and spatial technology to yield more precise information for the economic feasibility analysis. 


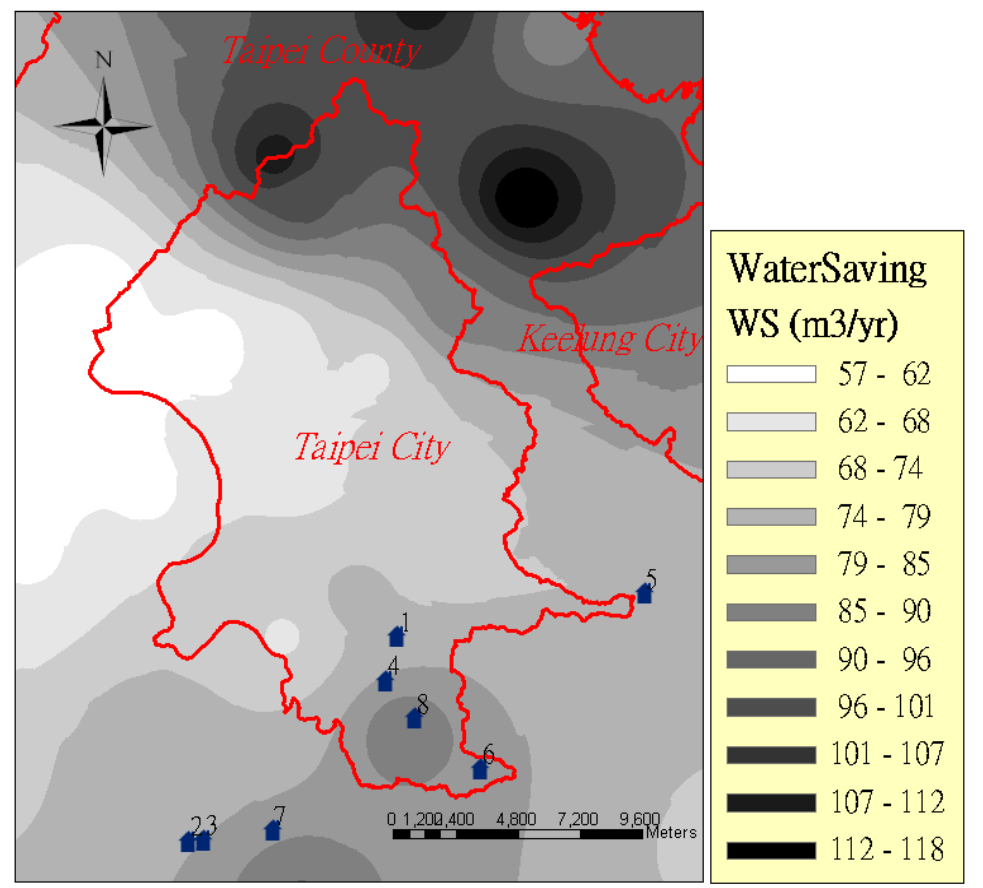

Figure 3. The locations of the communities, and the spatial variation of $W S\left(\mathrm{~m}^{3} /\right.$ year $)$ (assuming $A=90 \mathrm{~m}^{2}, V=3 \mathrm{~m}^{3}$ ) per household and rainwater used for toilet flushing and gardening.

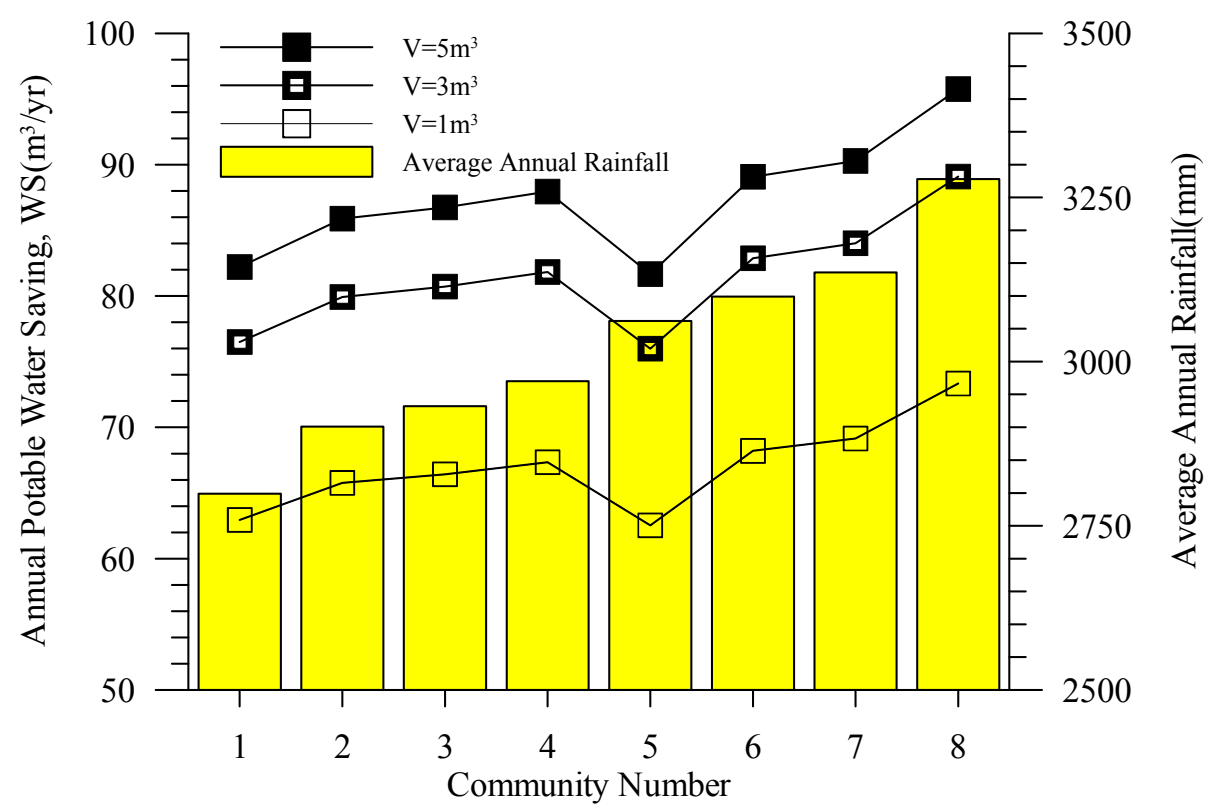

Figure 4. The average annual rainfall and WS of each community.

\subsection{Economic Feasibility Analysis and Optimal Design}

Figure 5 depicts and compares the results of the three scenarios used in the economic feasibility analysis of each community. This clearly indicates that all RWHSs of Scenarios 1 and 2 that considered only the benefits of water-saving, or only the benefits of energy-saving were unfeasible. This poor economic performance is partially because the Taiwanese government currently subsidizes water and electricity. In Scenario 3, which considered both water and electricity benefits combined, all 
RWHSs with smaller tank volumes were cost effective, and are therefore a feasible water-energy conservation scheme for hill communities. The findings of this study therefore demonstrate that considering energy and water use together provides valuable insights that do not arise from discrete analyses of only water or only energy.

Additionally, Scenario 3 in Figure 5 shows that the optimal tank volumes for each community could be obtained and are listed in Table 2. The approach demonstrated in Figure 5 is a simple and straightforward method to support users to determine the optimal RWHSs design on a large scale. Table 2 also includes the related $W S_{i}$ and energy savings factors required to calculate the total water-energy savings.

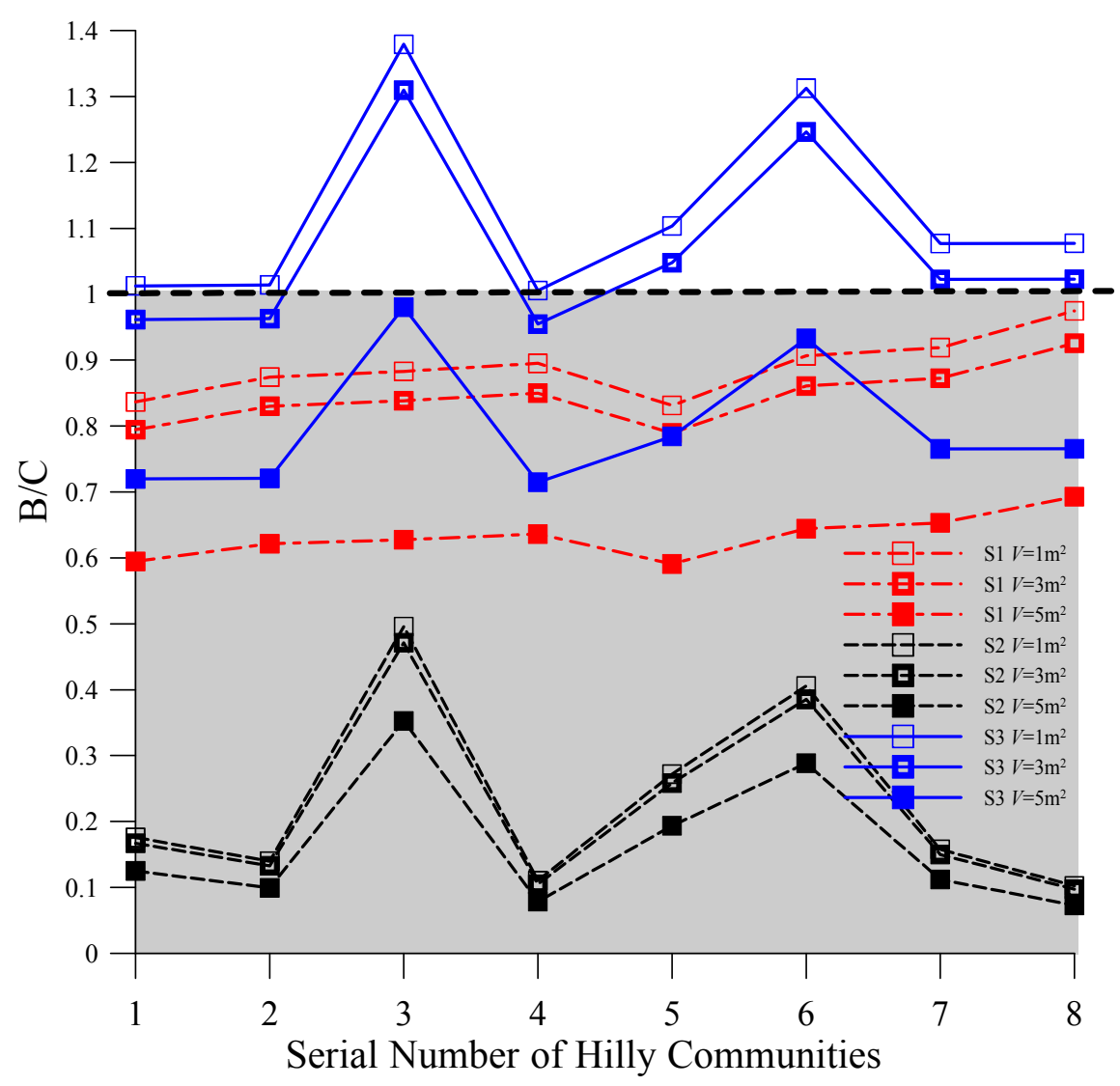

Figure 5. Results of economic feasibility analysis $\left(U W F=13 \mathrm{NT} \$ / \mathrm{m}^{3}, U E F=3 \mathrm{NT} \$ / \mathrm{kWh}\right)$.

Table 2. The optimal tank volumes and related water-energy saving details.

\begin{tabular}{|c|c|c|c|c|}
\hline$i$ & $\begin{array}{c}\text { Optimal Volume } \\
\qquad\left(\mathrm{m}^{3}\right)\end{array}$ & $\begin{array}{c}\text { Water Savings } \\
\left(\mathbf{m}^{3} / \text { year }\right)\end{array}$ & $\begin{array}{c}\text { Energy Savings } \\
\text { (kWh/year) }\end{array}$ & $\begin{array}{c}\text { Unit Energy Saving Cost } \\
(\mathrm{NT} \$ / \mathbf{k W h})\end{array}$ \\
\hline 1 & 1 & 62.9 & 85.0 & $17.1 *$ \\
\hline 2 & 1 & 65.8 & 71.3 & $21.5 *$ \\
\hline 3 & 3 & 80.7 & 228.1 & $6.4 *$ \\
\hline 4 & 1 & 67.3 & 62.3 & $27.2 *$ \\
\hline 5 & 3 & 76.0 & 141.3 & $11.7 *$ \\
\hline 6 & 3 & 82.9 & 197.4 & $7.8 *$ \\
\hline 7 & 3 & 84.0 & 99.5 & $20.0 *$ \\
\hline 8 & 3 & 89.1 & 79.7 & $30.8 *$ \\
\hline
\end{tabular}




\subsection{Contribution to Water-Energy Conservation}

Based on the optimal design, the total water savings should reach 307,173 $\mathrm{m}^{3} /$ year (i.e., $75.8 \mathrm{~m}^{3}$ per family per year). The total energy savings amounts to 561,438 (kWh/year) (i.e., an average of $138.6(\mathrm{kWh})$ per family per year). Households that use RWHSs could expect water savings equivalent to an average of $21.3 \%$ of domestic water use, or an energy saving of $21.3 \%$ for water pump costs in hilly areas.

\subsection{Comparison of RWHS with Solar Energy}

Growing awareness of the energy crisis and the effects of global warming are making solar PV systems increasingly popular in Taiwan, but the energy saving potential of RWHSs remains unknown to the public. Therefore, commercially available solar PV systems were selected for comparison. In Taipei, the UESC of installing PV systems has been reported to range from 28 to $30 \mathrm{NT} \$ / \mathrm{kWh}$ [49]. The UESC of RWHSs was calculated and is listed in Table 2. It ranged from 6.4 to $30.8 \mathrm{NT} \$ / \mathrm{kWh}$. The UESC of RWHSs in $85.5 \%$ of households, that is, seven communities out of eight, is lower than that of solar PV. Therefore, before the cost of PV panels decreases substantially, harvesting rainwater should be regarded as a feasible option to address the emerging water-energy demand of communities based in hilly areas surrounding large cities.

The GSBDS is a useful tool to evaluate and design RWHSs for water-energy conservation, and this case study demonstrates that RWHSs are feasible when both water and energy savings are considered. However, the feasibility and benefits of applying RWHS may be underestimated if only direct monetary benefit is considered. Indirect benefits, such as $\mathrm{CO}_{2}$ emission reduction, storm runoff mitigation, reducing water stress during peak hours, and decreased demand on current water and energy facilities, should not be overlooked when planning RWHS for urban development. This case study's data may not be applicable to all communities of the Taipei metropolitan area. Therefore, more community, building, and RWHS types should be considered in future studies before RWHSs can be fully implemented as an essential component of a water-energy conservation scheme for large cities.

\section{Conclusions}

Water-energy challenges can constrain ongoing development in many rapid growing cities. Therefore, a system to conserve rooftop rainwater in the hill communities surrounding the Taipei metropolitan area was systematically designed and evaluated in this study. We established a GSBDS to identify the hydraulic performance of RWHSs, quantify the economic feasibility of RWHSs for optimal design, and understand RWHSs water-energy saving potential.

Based on the spatial technology and water balance model of the GSBDS, the accuracy of evaluation was enhanced, and the hydraulic performance of RWHSs was quantified for economic analysis. Traditionally, water conservation efforts seldom incorporate energy conservation, however, the economic feasibility findings of this study strongly suggest that the economic feasibility is substantially enhanced when both water and energy savings are considered together. The results also revealed that, based on the optimal RWHS design derived from the economic feasibility analysis, the contribution of RWHSs to water-energy conservation can reach $307,173 \mathrm{~m}^{3} /$ year (i.e., $75.8 \mathrm{~m}^{3}$ per family per year) and 561,438 kWh/year (i.e., an 
average of $138.6 \mathrm{kWh}$ per family per year); which is an average of $21.3 \%$ savings in domestic water use, or a $21.3 \%$ energy savings in water pumping in hilly areas. Additionally, RWHSs are more cost-effective than solar PV systems for $85.5 \%$ of households in hill communities.

RWHSs are therefore not only a practical water-saving strategy, but also a feasible energy-saving approach. One of the advantages of a GSBDS is its ability to provide a systematic and comprehensive method to explore the energy and water savings of RWHSs on a city scale. Therefore, GSBDS is a useful tool to evaluate and design RWHSs to ease the growing water-energy shortage dilemma caused by rapid urbanization.

\section{Acknowledgments}

The authors wish to acknowledge the essential support and from Taipei Water Department and Jin Win University of Science and Technology.

\section{Author Contributions}

All authors were involved in designing and discussing the study. Yie-Ru Chiu executed the model and coordinated the group. Yao-Lung Tsai and Yun-Chih Chiang collected required data and finalized the manuscript. All authors have read and approved the final manuscript.

\section{Conflicts of Interest}

The authors declare no conflict of interest.

\section{References}

1. Cheng, C.L. Study of the inter-relation between water use and energy conservation for a building. Energy Build. 2002, 34, 261-266.

2. Jothiprakash, V.; Sathe, M.V. Evaluation of rainwater harvesting methods and structures using analytical hierarchy process for a large scale industrial area. J. Water Resour. Prot. 2009, 1, 427-438.

3. Proenca, L.C.; Ghisi, E.; da Fonseca Tavares, D.; Coelho, G.M. Potential for electricity savings by reducing potable water consumption in a city scale. Resour. Conserv. Recycl. 2011, 55, 960-965.

4. Scott, C.A.; Pierce, S.A.; Pasqualetti, M.J.; Jones, A.L.; Montz, B.E.; Hoover, J.H. Policy and institutional dimension of the water-energy nexus. Energy Policy 2011, 39, 6622-6630.

5. Plappally, A.K.; Lienhard, V.J.J. Energy requirement for water production, treatment, end use, reclamation, and disposal. Renew. Sustain. Energy Rev. 2012, 16, 4818-4848.

6. Varis, O.; Somlyody, L. Global urbanization and urban water: Can sustainability be afforded? Water Sci. Technol. 1997, 35, 21-32.

7. Douglass, M. East Asian Urbanization: Patterns, Problems, and Prospect; Asia/Pacific Research Center, Stanford University: Stanford, CA, USA, 1998.

8. Asian Development Bank (ADB). Thinking about Water Differently, Managing the Water-Energy-Food Nexus; Asian Development Bank: Mandaluyong, Philippines, 2013. 
9. Hightower, M.; Cameron, C.; Pate, R.; Einfeld, W. Emerging energy demands on water resources. Water Resour. Impact 2007, 9, 8-11.

10. Phoenix, L.E. Introduction: Energy and water. Water Resour. Impact 2007, 9, 1-3.

11. Talebpour, M.R.; Sahin, O.; Siems, R.; Stewart, R.A. Water and energy nexus of residential rain water tanks at an end use level: Case of Australia. Energy Build. 2014, 80, 195-207.

12. Farreny, R.; Gabarrell, X.; Rieradevall, J. Cost-efficiency of rainwater harvesting strategies in dense Mediterranean neighborhoods. Resour. Conserv. Recycl. 2011, 55, 686-694.

13. World Bank. Delivering water to Mexico City. Urban Age Mag. 1999, 6, 16-17.

14. Rees, W.E. Ecological footprints and appropriated carrying capacity: What urban economics leaves out. Environ. Urban. 1992, 4, 121-130.

15. Beal, C.; Bertone, E.; Stewart, R.A. Evaluating the energy and carbon reductions resulting from resource-efficient household stock. Energy Build. 2012, 55, 422-432.

16. Fewkes, A. The use of rainwater for WC flushing: The field testing of a collection system. Build. Environ. 1999, 34, 765-772.

17. Liaw, C.H.; Tsai, Y.L. Optimum storage volume of rooftop rainwater harvesting systems for domestic use. J. Am. Water Resour. Assoc. 2004, 40, 901-912.

18. Villarreal, E.L.; Dixon, A. Analysis of a rainwater collection system for domestic water supply in Ringdansen, Norrkoping, Sweden. Build. Environ. 2005, 40, 1174-1184.

19. Ghisi, E. Potential for potable water savings by using rainwater in the residential sector of Brazil. Build. Environ. 2006, 41, 1544-1550.

20. Chisi, E.; Ferreira, D.F. Potential for potable water saving by using rainwater and greywater in a multi-storey residential building in southern Brazil. Build. Environ. 2007, 42, 2512-2522.

21. Liaw, C.H.; Chiang, Y.C. Dimensionless analysis for designing domestic rainwater harvesting systems at the regional level in northern Taiwan. Water 2014, 6, 3913-3933.

22. Imteaz, M.A.; Ahsan, A.; Shanableh, A. Reliability analysis of rainwater tanks using daily water balance model: Variations within a large city. Resour. Conserv. Recycl. 2013, 77, 37-43.

23. Imteaz, M.A.; Matos, C.; Shanableh, A. Impacts of climatic variability on rainwater tank outcomes for an inland city, Canberra. Int. J. Hydrol. Sci. Technol. 2014, 4, 177-191.

24. Imteaz, M.A.; Rahman, A.; Ahsan, A. Reliability analysis of rainwater tanks: A comparison between South-East and Central Melbourne. Resour. Conserv. Recycl. 2012, 66, 1-7.

25. Fewkes, A.; Butler, D. Simulating the performance of rainwater collection and reuse systems using behavioural models. Build. Serv. Eng. Res. Technol. 2000, 21, 99-106.

26. Campisano, A.; Modica, C. Appropriate resolution timescale to evaluate water saving and retention potential of rainwater harvesting for toilet flushing in single houses. J. Hydroinformatics 2015, 17, 331-346.

27. Campisano, A.; Gnecco, I.; Modica, C.; Palla, A. Designing domestic rainwater harvesting systems under different climatic regimes in Italy. Water Sci. Technol. 2013, 67, 2511-2518.

28. Matos, C.; Santos, C.; Pereira, S.; Bentes, I.; Imteaz, M. Rainwater storage tank sizing: Case study of a commercial building. Int. J. Sustain. Built Environ. 2013, 2, 109-118.

29. Hajani, E.; Rahman, A. Reliability and cost analysis of a rainwater harvesting system in peri-urban regions of Greater Sydney, Australia. Water 2014, 6, 945-960. 
30. Matos, C.; Santos, C.; Bentes, I.; Imteaz, M.A.; Pereira, S. Economic analysis of a rainwater harvesting system in a commercial building. Water Resour. Manag. 2015, 29, 3971-3986.

31. Retamal, M.; Glassmire, J.; Abeysuriya, K.; Turner, A.; White, S. The Water-Energy Nexus: Investigation into the Energy Implications of Household Rainwater Systems; Institute for Sustainable Futures, University of Technology Sydney: Sydney, Australia, 2009.

32. Siddiqi, A.; Anadon, L.D. The water-energy nexus in Middle East and North Africa. Energy Policy 2011, 39, 4529-4540.

33. Abdallah, A.; Rosenberg, D. Heterogeneous residential water and energy linkages and implications for conservation and management. J. Water Resour. Plan. Manag. 2014, 140, 288-297.

34. Chiu, Y.R.; Liaw, C.H. Designing rainwater harvesting systems for large-scale potable water saving using spatial information system. Lect. Note Comput. Sci. 2008, 5236, 653-663.

35. Wei, H.; Li, J.L.; Liang, T.G. Study on the estimation of precipitation resources for rainwater harvesting agriculture in semi-arid land of China. Agric. Water Manag. 2005, 71, 33-45.

36. Hsieh, H.H.; Chengm, S.J.; Liou, Y.J.; Chou, S.C.; Siao, B.R. Characterization of spatially distributed summer daily rainfall. J. Chin. Agric. Eng. 2006, 52, 47-55. (In Chinese)

37. SuperGeo Technologies Inc. User's Menu of SuperGIS; SuperGeo Technologies Inc.: Taipei, Taiwan, 2004.

38. Chiu, Y.R.; Liaw, C.H.; Hu, C.Y.; Tsai, Y.L.; Chang, H.H. Applying GIS-based rainwater harvesting design system in the water-energy conservation scheme for large cities. In Proceedings of the IEEE 13th International Conference on Computer Supported Cooperative Work in Design (CSCWD 2009), Santiago, Chile, 22-24 April 2009; pp. 722-727.

39. McGhee, T.J. Water Supply and Sewerage; McGraw-Hill: Singapore, 1991.

40. Vieira, A.S.; Beal, C.D.; Ghisi, E.; Stewart, R.A. Energy intensity of rainwater harvesting systems: A review. Renew. Sustain. Energy Rev. 2014, 34, 225-242.

41. Mitchell, V.G.; McCarthy, D.T.; Deletic, A.; Fletcher, T.D. Urban stormwater harvesting-sensitivity of a storage behaviour model. Environ. Model. Softw. 2008, 23, 782-793.

42. Campisano, A.; Modica, C. Regional scale analysis for the design of storage tanks for domestic rainwater harvesting systems. Water Sci. Technol. 2012, 66, 1-8.

43. Water Resources Agency, Ministry of Economic Affairs. Available online: Http://www.wra.gov.tw/ ct.asp?xItem=34751\&ctNode=6259\&comefrom=1p (accessed on 12 April 2014).

44. Chiu, Y.R.; Liaw, C.H.; Chen, L.C. Optimizing rainwater harvesting systems as an innovative approach to saving energy in hilly communities. Renew. Energy 2009, 34, 492-498.

45. Architecture and Building Research Institute (ABRI). Evaluation Manual for Green Building in Taiwan; Ministry of the Interior: Taipei, Taiwan, 2015. (In Chinese)

46. Soil and Water Conservation Bureau (SWCB). Technical Guidelines of Water and Soil Conservation; Council of Agriculture: Taipei, Taiwan, 2014. (In Chinese)

47. Wung, T.C.; Lin, S.H.; Hung, S.M. Rainwater reuse supply and demand response in urban elementary school of different districts in Taipei. Resour. Conserv. Recycl. 2006, 46, 149-167. 
48. RELMA in ICRAF \& UNEP. Rainwater Harvesting Potential in Africa: A GIS Overview Volume One. Available online: Http://www.unep.org/pdf/RWH_in_Africa-final.pdf(accessed on 15 July 2014).

49. Architecture and Building Research Institute (ABRI). Final Report of Study on Solar Radiate Criterion for PV Design and Related Testing Standard; Ministry of the Interior: Beijing, China, 2005. (In Chinese)

(C) 2015 by the authors; licensee MDPI, Basel, Switzerland. This article is an open access article distributed under the terms and conditions of the Creative Commons Attribution license (http://creativecommons.org/licenses/by/4.0/). 